\title{
Tropical disease and imperial medicine in colonial Sri Lanka
}

\author{
Soma Hewa \\ School of Policy Studies, Queen's University, Kingston, Ontario, Canada, and School of Public Administration, \\ Guangzhou University, Guangzhou, China.
}

Correspondence: Prof. Soma Hewa

e-mail:hewa@queensu.ca

\begin{abstract}
For centuries, cultural imperialism was at the heart of the Western colonizing project around the globe. Economic and health policies were twin pillars that sustained the material and cultural hegemony over indigenous populations. Medicine played a pivotal role, both as a tool of the colonial expansion and a potent symbol of the superiority of Western culture. This paper examines the impact of economic and health policies on the lives of Indian migrant labourers and the indigenous people of Sri Lanka during British colonial rule.
\end{abstract}

Key words: Colonialism, disease, Rockefeller philanthropy, medicine

\section{Introduction}

Western medicine introduced by European colonizers and missionaries has been portrayed as "God sent" for millions of lives in Africa, Asia, and the Americas. Western medicine represented a higher civilization and social order that lifted the "backward" people to modern ways of life. Medical missionaries believed that the eradication of fatal diseases among the indigenous people would encourage the "heathens" to embrace Christianity (1). Commenting on the effort to establish a public health department in India by the British colonial government in the mid-nineteenth century, Florence Nightingale observed: "it was not only a noble task but also a part of a mission to bring a higher civilization into India" (2). However, even though Western medicine was regarded as an integral part of culture, medical services were rarely extended to the masses without reservations.

By contrast, several studies have argued that medicine and medical services in the colonies evolved in response to the political and economic needs of Western imperialism. They suggest that medicine played a critical role in the expansion of imperialism in the late nineteenth and early twentieth centuries (3). Medicine, as it was introduced to non-Western societies by imperial forces, was an instrument of political, economic, and cultural domination. With the expansion of European colonialism in Asia, Africa, and Latin America, the threat of "tropical disease" became a major obstacle to colonial rule. Malaria was the biggest enemy of the British troops in early nineteenth century Sri Lanka. From 1817 to 1836, among the military personnel serving in the island, the death rate per thousand was 75 compared to that of 15 per thousand in Britain during the same period. None of these deaths was due to military activity (4). The annual death rate among Europeans in West Africa in the late eighteenth century was between 300 and 700 per thousand - a scenario that led to Africa being called a "white man's grave" (5). New medical sciences were developed to deal with diseases such as cholera, malaria, dysentery, and yellow fever for the protection of the European troops and administrators from diseases originating in the indigenous communities. The fact that the impetus for the development of Western medicine in British India was the concern of the health of the British army and the European expatriates created medical "enclaves" across India that practically excluded the 
majority of the local populations. Such policies were justified by the colonial administrators who contended that the Indians were "superstitious and backward," and would not accept modern medicine even if it were offered (6).

Colonial economic and labor practices were major contributors to the spread of epidemic disease. Yet, medical services were not extended to local population until it became apparent that the health of the European personnel, particularly members of the military, could not be protected by measures directed at them alone (7). The growing trade and the demand for raw materials not only increased the exploitation of land and other resources, but also demanded the mass mobilization of cheap labor across colonies, a practice that directly contributed to the spread of disease.

Against this backdrop, we examine the impact of British colonial labor practices on the health of South Indian immigrant workers on the plantations and the local population of Sri Lanka (formerly known as Ceylon) as a case study. We contend that the laissez-faire policy of the colonial government empowered the British planters to ignore even the most basic sanitary requirements such as latrines on the plantations in order to maximize profit. As a result, the plantations became breeding grounds for many parasitic and infectious diseases found on the island during the late nineteenth and early twentieth centuries. When the International Health Board (hereafter IHB) of the Rockefeller Foundation arrived in Sri Lanka in 1916 to set up a hookworm control campaign, there was an epidemic of hookworm infection on the plantations and the neighboring villages.

Philanthropic medicine, which came to assist the British planters, also served the long-term political and economic interests of American industrial capitalism. Rockefeller philanthropic medicine failed to eradicate hookworm disease on the plantations because planters, not perceiving the mutual interdependence of their own economic interests and the health of the colonial labor, did not fully cooperate with the program (8).

\section{Historical background}

The British captured the Kandyan Kingdom of Sri Lanka in 1815, slaughtering thousands of natives and destroying scores of villages (Marshall 1846). Dr. Henry Marshall, a senior medical officer of the 89th Regiment that led the war against the Kandyan Kingdom, wrote that "the incursions of our troops into the Kandyan territory... were calculated to fill the population with the most unfavorable opinions of our justice and humanity, and to confirm the worst prejudices against the European race" (9). As Marshall predicted, the resentment of the Kandyan Sinhalese towards British rule persisted. When the British established plantation industries in central Sri Lanka during the mid-nineteenth century, the Kandyans refused to work on the estates. To fill this deficit, laborers were brought from the Southern Indian state of Tamil Nadu for the year-round work in the plantation industry (figure 1). By the turn of the century, about 100,000 workers and their families arrived annually in Sri Lanka. The sanitary conditions on the estates were deplorable (10).

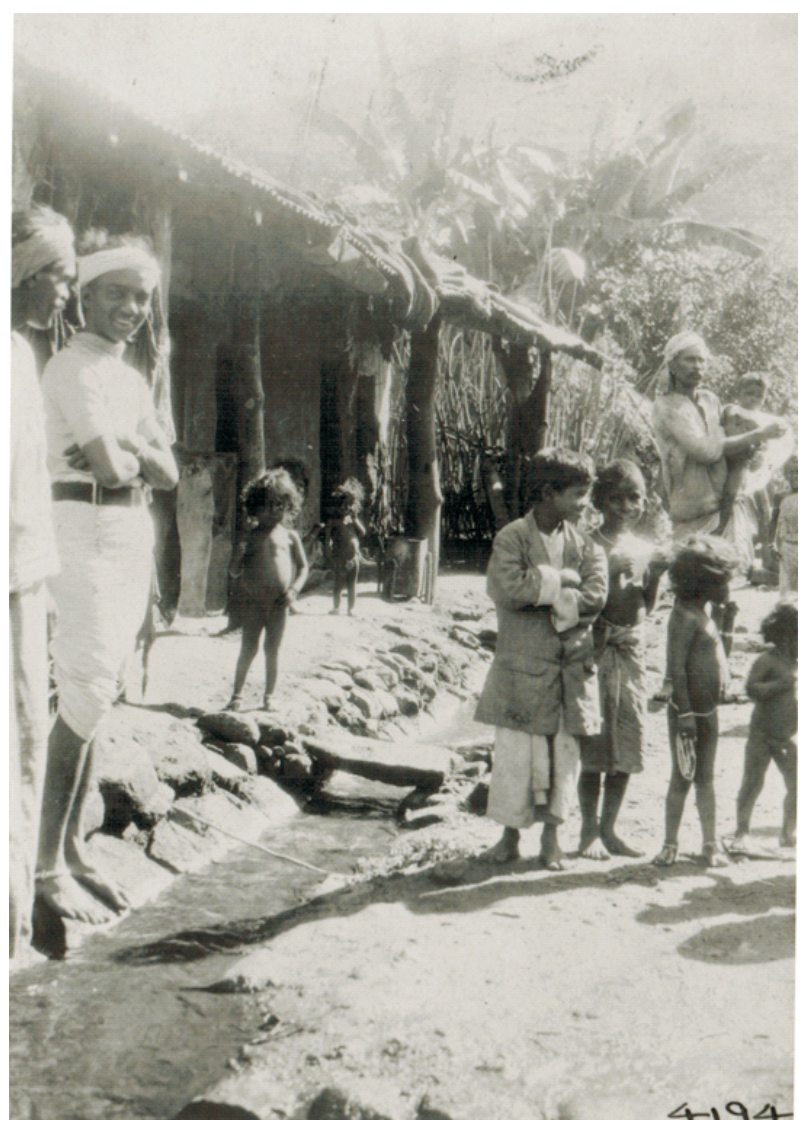

Figure1: A typical workers' line on the plantations.

Courtesy of the Rockefeller Archive Center 


\section{Hookworm epidemic on the plantations}

Hookworm infection was first reported in the administration report of the Principal Civil Medical Officer (PCMO) of Sri Lanka in 1888, when 31 cases were diagnosed at hospitals in Colombo, Badulla, and Kurunegala (11). This number increased rapidly and by 1899 , about 239 deaths from anchylostomiasis had been reported on the island. According to Allan Perry, PCMO, over 80 percent of the reported cases were immigrant workers, and the rest were people living in the neighboring villages of the plantation areas. Although the authorities were fully aware of the cause of the disease, they were reluctant to interfere with the private economic decisions of the planters. Despite the fact that a large number of the immigrant laborers arriving in Sri Lanka each year seldom lived more than "a couple of monsoons," the planters were not bothered with the high death toll. According to historians, in the years between 1841 and 1848 , about 70,000 $(10,000$ per year) or 25 percent of the immigrant workers died of various causes (12). By 1916, the hookworm disease had reached epidemic proportions. As Table 1 shows, more than 90 percent of the population on the $\overline{\text { plantations }}$ was infected with the disease (figure 2).

Large European firms owned the plantations. In general, the business dealings of these firms were mostly conducted directly with the Colonial Office in London, which was sympathetic to these large firms. This allowed the firms and their estate companies to ignore the local policies of specific colonies, including those of Sri Lanka. For a variety of ideological, political and economic reasons, both the colonial government and planters prevented effective control of the hookworm disease on the plantations. The official viewpoint was that the hookworm disease on the plantations was a problem for the planters to deal with in accordance with their own economic objectives. The planters, on the other hand, perceived no direct economic benefit from controlling and curing the hookworm disease. This stalemate persisted throughout the late nineteenth and early twentieth centuries, directly contributing to a great deal of suffering among the immigrant laborers. It was against this background that the IHB decided to conduct a hookworm treatment program on the plantation in Sri Lanka.

Table 1: Death from Hookworm Infection, Sri Lanka 1900 - 1922

\begin{tabular}{|c|c|c|c|c|c|c|c|}
\hline \multirow{3}{*}{$\begin{array}{l}\text { Year } \\
1900\end{array}$} & \multicolumn{2}{|c|}{ Estimated Population $^{a}$} & \multirow{2}{*}{$\begin{array}{c}\begin{array}{c}\text { Death Rate } \\
\text { Per Million }\end{array} \\
72.3\end{array}$} & \multirow{3}{*}{$\begin{array}{r}\text { Year } \\
1913\end{array}$} & \multicolumn{2}{|c|}{ Estimated Population ${ }^{a}$} & \multirow{2}{*}{$\begin{array}{r}\begin{array}{l}\text { Death Rate } \\
\text { Per Million }\end{array} \\
534.7\end{array}$} \\
\hline & Island & $3,565,954$ & & & Island & ” & \\
\hline & Plantation & 441,601 & 217.3 & & Plantation & $"$ & 3449.1 \\
\hline \multirow{2}{*}{1904} & Island & $"$ & 88.3 & \multirow{2}{*}{1914} & Island & ” & 641.6 \\
\hline & Plantation & $"$ & 346.4 & & Plantation & ” & 4348.8 \\
\hline \multirow{2}{*}{1905} & Island & $"$ & 157.6 & \multirow{2}{*}{1915} & Island & $"$ & 504.0 \\
\hline & Plantation & $"$ & 656.7 & & Plantation & $"$ & 3269.9 \\
\hline \multirow{2}{*}{1906} & Island & $"$ & 256.5 & \multirow{2}{*}{1916} & Island & $"$ & 610.0 \\
\hline & Plantation & $"$ & 1173.0 & & Plantation & $"$ & 4021.6 \\
\hline \multirow{2}{*}{1907} & Island & 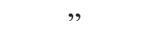 & 266.6 & \multirow{2}{*}{1917} & Island & $"$ & 624.6 \\
\hline & Plantation & $"$ & 1259.0 & & Plantation & ” & 4035.3 \\
\hline \multirow{2}{*}{1908} & Island & $"$ & 352.2 & \multirow{2}{*}{1918} & Island & ” & 566.9 \\
\hline & Plantation & $"$ & 1893.1 & & Plantation & $"$ & 3458.8 \\
\hline \multirow{2}{*}{1909} & Island & $"$ & 416.7 & \multirow{2}{*}{1919} & Island & $"$ & 635.1 \\
\hline & Plantation & $"$ & 2497.7 & & Plantation & $"$ & 3412.0 \\
\hline \multirow{2}{*}{1910} & Island & $"$ & 446.4 & \multirow{2}{*}{1920} & Island & $"$ & 794.1 \\
\hline & Plantation & $"$ & 2586.0 & & Plantation & $"$ & 4307.9 \\
\hline \multirow{2}{*}{1911} & Island & $4,106,350$ & 489.7 & \multirow{2}{*}{1921} & Island & $4,498,605$ & 651.3 \\
\hline & Plantation & 513,467 & 2894.0 & & Plantation & 568,850 & 3678.9 \\
\hline \multirow{2}{*}{1912} & Island & $"$ & 448.8 & \multirow{2}{*}{1922} & Island & $"$ & 415.4 \\
\hline & Plantation & ” & 3075.1 & & Plantation & $"$ & 2132.5 \\
\hline
\end{tabular}

${ }^{a}$ Population figures for the Island and the Plantations are based on the 1900, 1911, and 1921 census. Department of Census and Statistics. Census Data, Ceylon Year Book, Colombo 1970; Rockefeller Archive Center, Ceylon Population, 4, 1914, Record Group 5, Series 2, Box 47; Sri Lanka National Archive, Ceylon Ceylon Year Book, Colombo 1970; Rockefeller Archive Center, Ceylon Population, 4, 1914, 


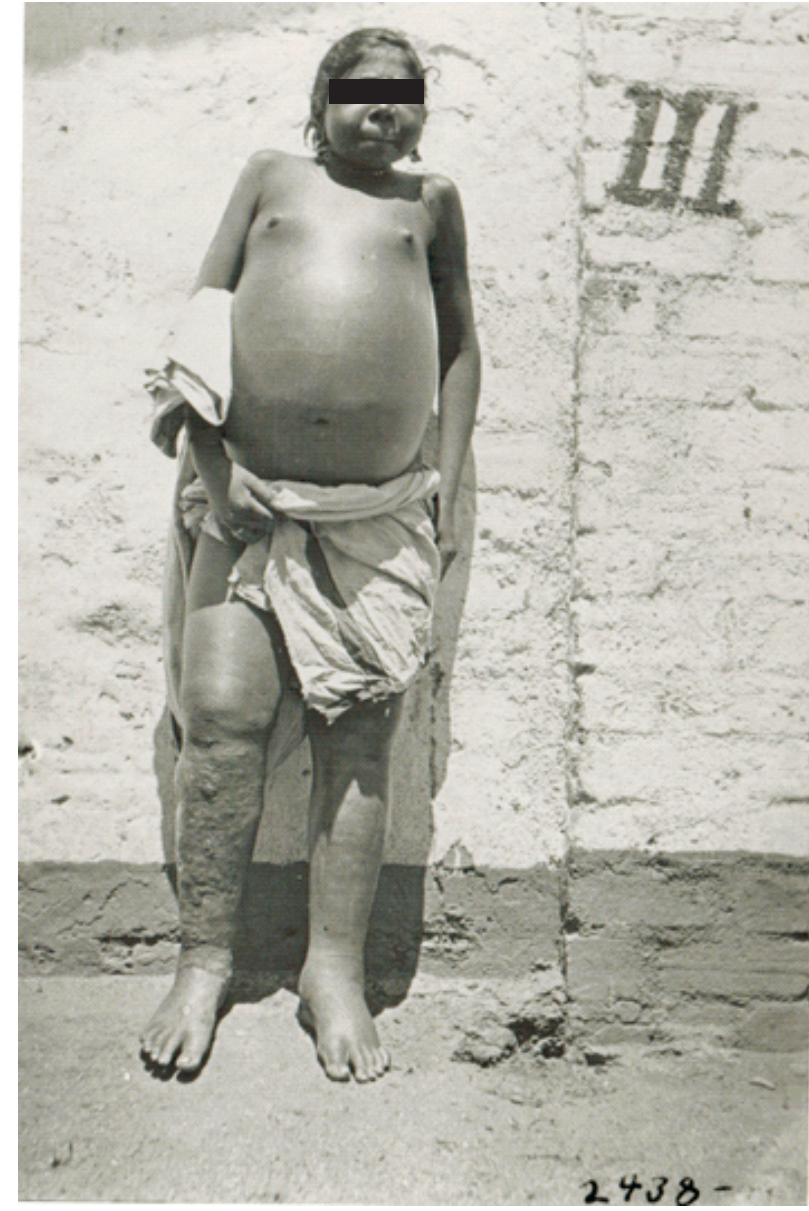

Figure 2: A severely infected plantation worker. Courtesy of the Rockefeller Archive Center

\section{Rockefeller philanthropic medicine in Sri Lanka}

The IHB arrived in Sri Lanka in 1915 and began negotiating with both the colonial authorities and the management of the plantations in the hope of establishing a hookworm treatment program on the estates. From the outset, both the colonial government and the planters opposed any outside interference in their work, arguing that it would ruin their business. However, determined to convince both the planters and the colonial authorities of the vital importance of the treatment campaign for their business interests, Dr. Victor Heiser, the director of the IHB operations in the East, presented his case from an economic point of view. He argued: "a healthy labourer is an asset to an estate while an unhealthy labourer is a partial liability. It appears economical therefore to keep laborers healthy." Dr. Heiser further strengthened the argument by pointing out: "disease never stays at home in its natural breeding place of filth, but is ever and again breaking into the precincts of its more cleanly neighbors" (13). He noted that the IHB was prepared to bear more than half the cost of the project, an incentive that neither the government nor the planters could refuse. In the end, he succeeded in persuading them to allow the IHB to begin the treatment campaign on the plantations.

With the approval of the colonial government and the planters, the IHB began a hookworm control program in 1916 in a selected group of estates. The representatives of the IHB, Drs. J. E. Snodgrass, W. C. Sweet and W. P. Jacocks, developed a working plan for Sri Lanka that was to be supervised by American medical personnel appointed by the IHB. The government also promised to provide "every legitimate assistance" to the planters to improve sanitary conditions. This was an important change in government policy toward the plantation industry. An area of about 7 by 10 miles in the Matale district, comprising 24 estates with a population of approximately 10,000 , was selected for the initial stages of the campaign. The program was gradually extended to other estates. Besides the treatment of those infected, the campaign consisted of experimenting with suitable types of latrines for the estates, paired with an information campaign about the cause and prevention of hookworm disease. In addition, the estate pharmacists were trained to diagnose the infection using microscopic and clinical techniques, and to administer proper doses of chenopodium oil as treatment (14).

By the end of 1917, the hookworm control campaign had treated about 40,000 people. Of these, 78 percent were pronounced cured upon microscopic reexamination. In addition, morbidity statistics were gathered from several estates, which showed the improvement in general health following the treatment for hookworm disease. The District Medical Officer of Matale reported that only 2,604 patients were admitted to hospitals in 1918, compared to 3,694 hospital admissions in 1916 before the hookworm control program was begun, a reduction of 27 percent (15).

In spite of these improvements in the health of workers, they were not enough to convince the planters to undertake the major sanitary improvements suggested by the IHB. As has been 
noted, the crucial requirement for the control of hookworm disease was the construction of latrines. Although the planters had agreed to construct latrines at the beginning of the campaign, they did not honor their commitment. With pressure from the IHB, the government introduced legislation making it compulsory for all the estates to provide sufficient latrines for the workers' lines. While many estates constructed latrines to comply with the law, they used temporary materials that lasted only a few weeks (figure 3). The unabated soil pollution on the plantations combined with the arrival of infected new workers from India ensured a high rate of reinfection. At the end of 1919, three years after the completion of treatment, an examination of a sample of about 3,000 workers showed that the infection had not declined (16).

\section{Failure of the hookworm control campaign}

The hookworm control campaign on the plantations could not achieve its goal because the sanitary conditions were not improved while the treatments were being carried out. At this point, it became clear to the IHB that neither the government nor the planters were seriously concerned about the hookworm problem. Although sharing the cost of the program, the government was not fully committed to the objective of improving sanitary conditions on the estates. It did not want to antagonize the powerful planters by forcing them to construct latrines, nor did it want to take over the construction of latrines on the estates, as this might appear to be a change of the government's policy toward the plantations. The planters, for their part, believed that they could overcome the persistent complaints against them by letting the hookworm control campaign treat their labourers. However, anything that required capital spending was not something that they were prepared to undertake.

By the end of 1922, according to the annual reports, the IHB had spent $\$ 195,048$ for the hookworm control campaign in Sri Lanka. The campaign had treated a total of 413,175 individuals on the estates and neighboring villages. This amounted to less than 50 cents per person. The government provided for the salaries and expenses of local subordinate staff, drugs, equipment, offices and office supplies. The annual reports of the IHB describe the government's spending as "an approximately equal division of the expense of the work". If that was the case, it can be suggested that from 1916 to 1922 the IHB and the government jointly spent about $\$ 400,000$ for the hookworm control program on the plantations (17).

The deaths from hookworm disease did not decline during this period. For example, out of ten major plantation districts where extensive treatments had been carried out, in only one district (Matale) had the number of deaths been reduced (by 13 per cent) between 1916 and 1919. In all the others, hookworm-related deaths continued to increase during the campaign, with disproportionately high numbers from 1917 to 1918 , which were the years of the influenza epidemic. When the campaign began in 1916, an average hookworm-related death rate for these ten districts was 520, which rose to a peak of 619 in 1919. Several explanations have been given for this increase: 1) that doctors became aware of the disease and were making facile diagnoses, resulting in the attribution of more deaths to hookworm infection; 2) a rice shortage on the plantations during the World War I changed the diet to rougher foods which aggravated the disease; 3 ) for the first time, an administrative mechanism was developed to obtain accurate registration of vital statistics in 1919.

Despite these official interpretations of the increased deaths during the campaign, one cannot overlook the fact that the treatments could not prevent continued re-infection due to the poor sanitary conditions. Although the campaign reduced the number of worms each infected individual harbored, the rate of re-infection increased over time with the unabated soil pollution. This was the major factor that was never adequately tackled on the estates. Almost every annual report of the project directors and field doctors referred to the poor sanitary conditions, but the planters and the government always brushed off the problem with temporary solutions. Given the transparent importance of sanitation in controlling hookworm disease, it is hard to comprehend why the construction of latrines on the plantations was not given priority in the hookworm control campaign. It is in response to this question that the remainder of the paper is addressed. 


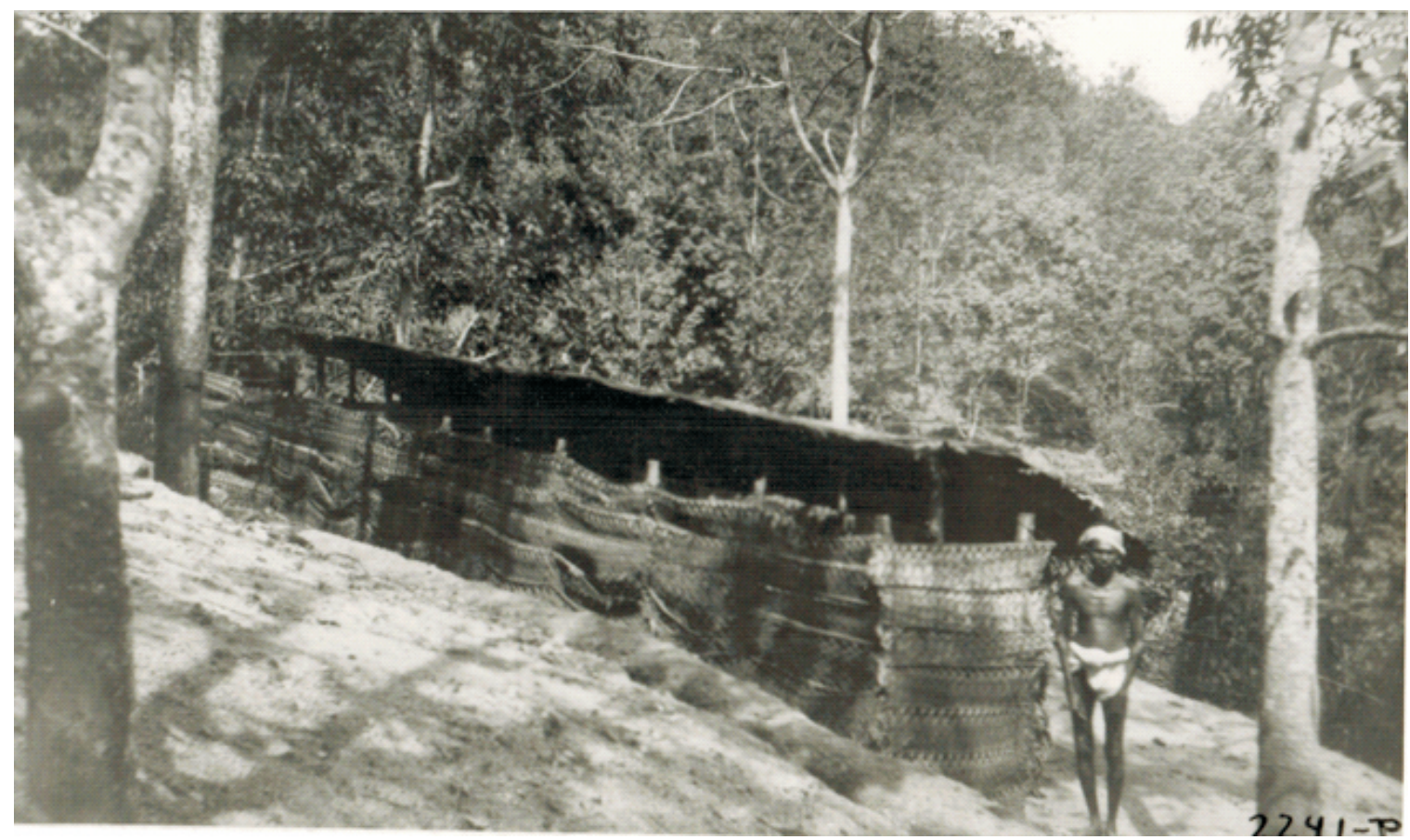

Figure 3: An example of latrines built on a plantation - Courtesy of the Rockefeller Archive Center

Leaving aside the callous treatment of those in their employ, it should be clear that the planters' unwillingness to construct latrines rested principally on the issue of profit. They knew that it would cost them a certain amount of money to build the necessary permanent latrines and they perceived no economic or legal impediments to disregard such needs. The sanitation problem caused no serious labour shortages, owing to the ready supply of workers from India. Further, the planters enjoyed relative immunity from prosecution for failure to comply with even those sanitary regulations already in place. For its part, having begun to experience a degree of cordiality with the planters by the time of the program's implementation, the government seems to have been reluctant to press its legal hand over the matter of sanitation. The arrival of Rockefeller "philanthropic" medicine provided the government with some means to move away from its mutually confrontational relations with the planters in a way that would not jeopardize its dubious laissez-faire policy. The government was decidedly unwilling to accept responsibility for sanitary services as it reasoned this might - in the perception of the planters - appear to be a retreat from its own (self-serving) policy of non-interference. Realizing that endorsement of the hookworm campaign was necessary, given the influence of the planters on the Colonial Office in London, the government of Sri Lanka eventually acquiesced perceiving no harm in playing a supportive role in the campaign. But the government's stated goal of eradicating hookworm disease was not its primary objective. This led to the curious result that it spent what was for that time a considerable amount of money in a largely futile exercise.

Finally, what accounts for the Rockefeller doctors' own failure to pursue more vigorously the importance of sanitary reforms on the plantations? Owing to past experience in elsewhere, the Rockefeller doctors were fully cognizant of the crucial relationship between latrines and the hookworm infection. The project director and the field doctors made frequent reference to the necessity of latrines on the plantations in their reports. The temporary latrines, which were constructed during the campaign, lasted only a few weeks, after which the problem of sanitation again became the major concern. From the beginning of the IHB's sojourn in Sri Lanka, senior representatives employed formidable diplomatic tact in bringing together the two hostile parties - the government and the planters - in order to initiate 
the campaign on the plantations. To a certain extent it would seem that this rhetorical theme of diplomacy became the predominant tenor of discourse, imbuing all subsequent relations. And since it was so important in initiating the campaign, it was difficult to interrupt. As a result, the representatives of the IHB were required to play the role of mediator or broker between the government and planters, which compromised their ability to advocate sanitary reforms more forcefully in conjunction with treatments. Moreover, despite the field doctors' continual reporting of the sanitary problems on the plantations, there was no significant effort on the part of high-ranking officials to convert these concerns into tangible reforms (18).

However, there is another dimension to the failure of the hookworm campaign in Sri Lanka. It is that, being both trained and socialized by the theories and values of Western medicine, the medical personnel involved were products of, and enamored with, the emerging biomedical model. The IHB did not pursue the question of latrines forcefully with either the government or the planters because its aim was to cure the disease. For the Rockefeller Foundation, eradication of hookworm disease meant not only the increased productivity of labour but also a wider acceptance of Western cultural values by the people of European colonies. This was considered to be crucial for the future of American economic and political interests in those countries. It is ironic that the money spent on treatment could easily have provided a sufficient number of functioning latrines on the plantations. In spite of the persistent suggestions by the field doctors regarding the urgency of sanitation, the prevention of hookworm disease was never - not in an unequivocal manner, at least - considered an indispensable part of the agenda. This is because the main concern of the senior officials of the IHB was to "demonstrate" the curative power of Western medicine. In conclusion, it can be suggested that the control of hookworm disease through sanitary reforms was less alluring to the senior officials of the IHB and, consequently, was judged by them to be a less impressive display of Western culture in the ongoing publicity campaign.

\section{NOTES:}

Due to space limitation only a minimum number of archival sources are listed here. Interested readers can find a full account of archival materials on this topic in my book: Hewa, S 1995 Colonialism, Tropical Disease and Imperial Medicine: Rockefeller Philanthropy in Sri Lanka, Lanham, Maryland, University Press of America.

\section{Reference}

1. Comaroff J, Comaroff J. (1992). Ethnography and the Historical Imagination, pp. 215-233, Boulder, Westview Press.

2. Cook E. (1914). The Life of Florence Nightingale, Vol. 2, p. 1, London, Macmillan Press.

3. Headrick RD. (1981). The Tools of Empire: Technology and European Imperialism in the Nineteenth Century, New York, Oxford University Press; Arnold, D (1988) "Introduction," pp. 1-26, in D. Arnold (ed.) Disease, Medicine and Empire: Imperial Medicine and Indigenous Societies, Manchester, Manchester University Press.

4. Uragoda CG. (1987). A History of Medicine in Sri Lanka, from the earliest time to 1948, Colombo, Sri Lanka Medical Association.

5. Curtin PD. (1961). "The White Man's Grave: Image and Reality, 1780-1850," Journal of British Studies, 1: 94-110; Curtin PD. (1989). Death By Migration, Europe Encounter With the Tropical World in the Nineteenth Century, Cambridge, Cambridge University Press.

6. Ramasubban R. (1988). "Imperial Health in British India, 1857-1900," pp. 38-60, in R. Macleod and M. Lewis (eds.), Disease, Medicine, and Empire: Perspectives on Western Medicine and the Experience of European Expansion, New York, Routledge.

7. Worboys M. (1988). "Manson Ross and Colonial Medical Policy: Tropical Medicine in London and Liverpool 18991914,” pp. 21-37, in R. MacLeod and M. Lewis (eds.) Disease, Medicine and Empire: Perspectives on Western Medicine and the Experience of European Expansion, New York, Routledge.

8. Hewa S. (1994). "The hookworm epidemic on the plantation in Colonial Sri Lanka," Medical History, Vol. 38, 1:73-90.

9. Marshall H. (1846). Ceylon, A General Description of the Island and its Inhabitants, London, pp.120-21. 
10. Rockefeller Archive Center (hereafter RAC), Ceylonsanitary and health conditions-hookworm disease, 1-5, 1914, Record Group (RG) 5, series 2, Box 47.

11. Sri Lanka National Archive (hereafter SLNA), Ceylon: Admin. Reps, Colombo: PCMO and IGH, 1888), pp.11-12.

12. de Silva KM. (1965). Social Policy and Missionary Organizations in Ceylon1840-1855, London, Longmans, for the Royal Commonwealth Society, p. 239.

13. Heiser V. (1936). American Doctor's Odyssey, New York, W.W. Norton and Company, pp. 327-29.
14. RAC, Working plan for the relief and control of anchylostomiasis in Ceylon, 1916, 1-3, RG 5, series 2, box 48.

15. RAC, Relief and control of hookworm disease in Ceylon, 1918, 27-37, RG 5, series 2, box 47.

16. RAC, Ibid, pp. 18-20.

17. RAC, Relief and control of hookworm disease in Ceylon, 18-20, 1920, RG 5, series 2, box 47, pp. 23-4.

18. RAC, Letter from Dr. W.P. Jacocks to Dr. Victor Heiser, May 24, 1920, No 1132 RG5, series2 Box 47. 